\title{
Prevention Based Incremental Oral Health Care by use of the Individual Oral health Index
}

\author{
Shin Seung Chul ${ }^{1}$ and Chang Yeon Soo ${ }^{2 *}$ \\ ${ }^{1}$ Preventive Dentistry, Korea \\ ${ }^{2}$ Department of Research Institute on Clinical Dentistry, Korea
}

*Corresponding author: Chang Yeon Soo, Department of Research Institute on Clinical Dentistry, Praha Dental Clinic, Korea

\begin{tabular}{|c|c|}
\hline ARTICLE INFO & ABSTRACT \\
\hline Received: 慧 June 18, 2019 & Citation: Shin Seung Chul, Chang Yeon Soo. Prevention Based Incremental Oral Health \\
\hline Published: 幽 June 25, 2019 & $\begin{array}{l}\text { Care by use of the Individual Oral health Index. Biomed J Sci \& Tech Res 19(1)-2019. } \\
\text { BJSTR. MS.ID.003255. }\end{array}$ \\
\hline
\end{tabular}

\section{Introduction}

The ideas of the prevention first, treatment back-up and the minimum intervention for the oral disease are the World Health Organization concept to control the health care. But this principle has not been applied in many of the capitalism-based countries in the world as well as in Asia, where the most of the dental health cares have been managed by the private dental clinics and dental hospitals. That is due to the difference of the dental income for each treatment, as the cheap in prevention and the more income for treatment and rehabilitation as dental prosthodontic care or dental implant. So, it should be needed to develop the new system for encourage the preventive cares more even though in capitalism countries, and the idea has been suggested through applying the prevention based continuous dental care system by developing the individual oral health index for each dental patients who visit the dental clinics. As the results of this program, the dental incomes would be increased by the increase of the patron patients, and the goal for more delivery of the prevention can be realized gradually [1-4].

\section{Body}

Such 5 factors would be considered to develop the individual oral health index as the numbers and sound state of the residual natural teeth, caries state, periodontal state, the other oral health state as TMJ, malocclusion, oral infection, malformation, fractured tooth, esthetic or oral malodor, and so on, oral hygiene state, oral micro-organism and caries activity and care habits and the last item for the systemic body conditions. 5 influencing factors and sub factors should be considered with the different weight for the individual oral health according to 6 age groups as preschool child, child, adolescent, young adult, middle aged and aged people. The different weight of each factors and sub factors were examined by regression model as one of the statistics methods with several times clinical experiments for many years. The computer system was used to defined and calculate the individual score of the oral health points by putting the results of checking with 5 factors and sub factors one by one. R-program with pentagon shaped diagram is used to show the results of the individual oral health index to each patient for easy understanding $[5,6]$. The computer program for checking individual oral health index is compose with the following process as the different questionnaire by age group after checking the individual personal identification and facial photo taking to put it at individual dental chart to express as the one of the family of this dental clinic.

On next page, (Table 1) it show the oral photo for 6 cuts with smart phone camera or DSLR camera and then put all oral photos put at the digital chart to find the oral exam and recording the caries or filled state later, and then finishing to check the caries state. On the third page, (Figure 1) panorama X-ray digital photo was inserted in order to find the tentative state of the periodontal problems by observing the alveolar bone level and the root state for the periodontium. Also, the tentative other oral health state will be checked in this page. The $4^{\text {th }}$ page show the oral hygiene state by inserting the photos for plaque deposit state on the tooth surfaces staining with red colored disclosing solution and calculate for oral hygiene score at every times for dental visit. Oral micro- 
organism and caries activity would be checked by use of the phase contrast microscope and Modified Snyder test kit and the tentative results would be recorded on the chart [7]. After finishing 5 pages above, it will show the individual oral health index will be shown automatically on the next page with R-program and pentagon shaped diagram, and moreover it show the suggestion for the recommendation for the frequency of the dental visit per year and the date for proper items of the preventive dental cares at each time.

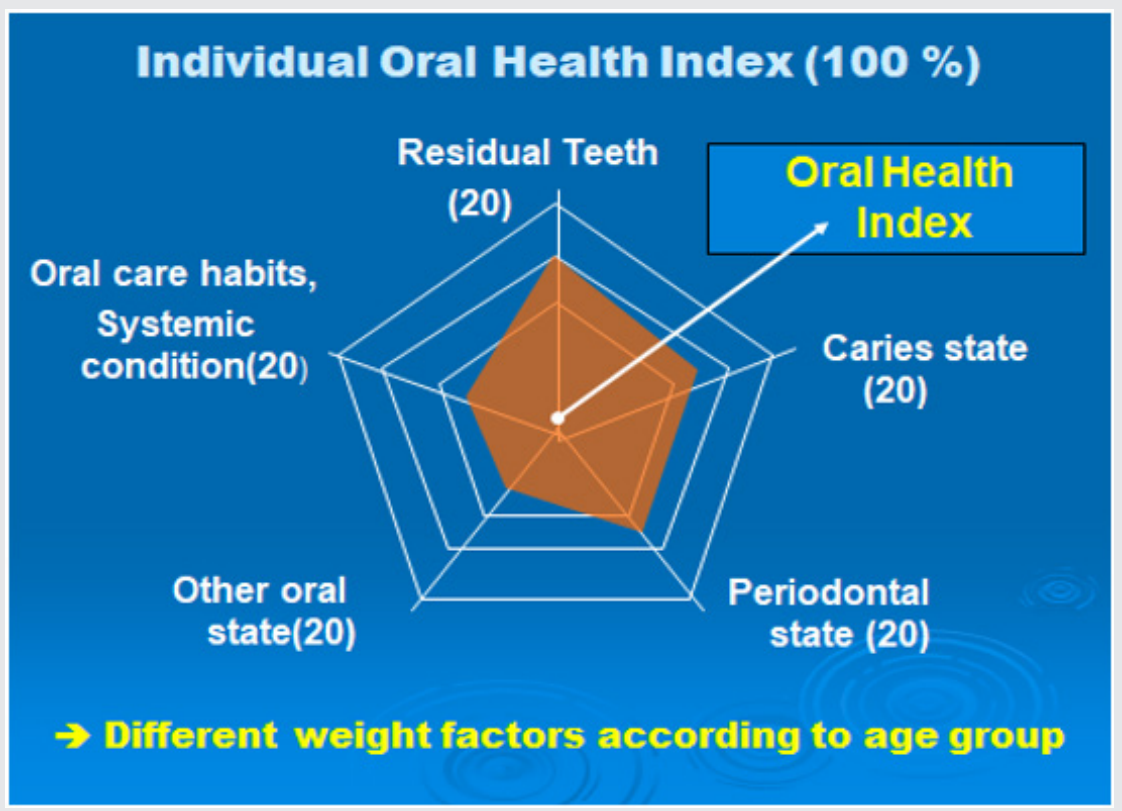

Figure 1: Diagram of Oral Health Index.

Table 1: The different relative weight for each factor according to the age group (\%).

\begin{tabular}{|c|c|c|c|c|c|c|}
\hline Age Gr. & \multirow{2}{*}{ Preschool Child } & \multirow{2}{*}{ School Child } & \multirow{2}{*}{ Adolesce-nt } & Young & Prime of & Aged \\
\cline { 1 - 4 } & & & & Adult & Manhood & person \\
\hline N. of Tooth & 20 & 20 & 20 & 15 & 18.8 & 19.9 \\
\hline Caries state & 40 & 31.6 & 35.2 & 29.9 & 19.5 & 16.8 \\
\hline Period. state & 10.5 & 11.2 & 11.8 & 21.6 & 17.2 & 27.2 \\
\hline Other Health & 11.5 & 17.7 & 15.3 & 14.7 & 18.6 & 21 \\
\hline Habit/Systemic & 18 & 19.4 & 17.7 & 18.8 & 15.1 \\
\hline
\end{tabular}

\section{Conclusion}

The incremental and continuous dental care system by use of the individual oral health index with the computer program was effective to supply the preventive cares to dental patients and to expand the preventive cares at the dental fields in the capitalism countries. It has been applied at some dental clinics with successfully as a family dentist system with the preventionbased measures, in Korea, and I believe this system will be speeded gradually in the future to agree the WHO slogan as prevention first dental cares even in capitalism countries.

\section{References}

1. Kim HJ (2009) Caries Prediction Model according to influencing Factors on Dental Caries. Int J Clin Prev Dent 5(3): 177-195.

2. Paik DI, Park YD, Shin SC (2011) Clinical Preventive Dentistry ( $5^{\text {th }}$ edn.). KoMunSa pp. 411-429.
3. Seo DH, Cho JW, Chang YS (2010) Analysis in the Influence Factors on the Periodontal Health. Int J Clin Prev Dent 6(4): 139-145.

4. Kim DH, Park JH, Yun MH, Shin SC, Cho JW, et al. (2014) The Differential Weight of Factors foe Estimation of Individual Oral Health Index Int J Clin Prev Dent 10(1): 37-44.

5. Hwang JH, Yu KJ (2016) Oral Health Index for Preschool Children and School Children by use of a Computer program for the Incremental Dental Care System Int J Clin Prev Dent 12(2): 65-71.

6. Yoon SH, Joeng MK, Lee CH (2016) Proper Range Decision for each Level of the Individual Oral Health Index Score for Incremental Dental Care System in Prime of Manhood and Aged People Int J Clin Prev Dent 12 (3): 185-193.

7. Cho BR, Min KH (2017) Proper Range Decision for each Level of the Individual Oral Health Index Score for Incremental Dental Care System in Adolescence and Young Adults. Int J Clin prev dent 13(3): 141-146. 
ISSN: 2574-1241

DOI: 10.26717/BJSTR.2019.19.003255

Chang Yeon Soo. Biomed J Sci \& Tech Res

(c) (P) This work is licensed under Creative Commons Attribution 4.0 License

Submission Link: https://biomedres.us/submit-manuscript.php

$\begin{array}{ll}\text { BIOMEDICAL } & \text { Assets of Publishing with us } \\ \text { RESEARCHES } & \text { - Global archiving of articles } \\ & \text { - Immediate, unrestricted online access } \\ & \text { - Rigorous Peer Review Process } \\ \end{array}$

